\title{
Subproduto da vitivinicultura no controle do míldio e indução de enzimas de defesa em videira
}

By-products of vitiviniculture in the control of downy mildew and induction of defense enzymes in grapevine

Subproducto de la viticultura sobre el control del mildiú velloso y la inducción de enzimas de defensa en la vid

\section{Resumo}

Na elaboração de vinhos é obtido uma grande quantidade de resíduos que podem conter composto com ação antimicrobiana e indutora. Neste sentido, o objetivo do trabalho foi verificar a ação do extrato aquoso do resíduo de uva (EARU) no controle do míldio e ativação de enzimas de defesa em videiras cv. Margot. Os tratamentos utilizados foram: EARU a 12\%, Saccharomyces cerevisae (Agro-Mos®), calda bordalesa (CB) e água (testemunha). Foi realizado teste de germinação de Plasmopara viticola, área abaixo da curva do progresso da doença (AACPD) de míldio em discos de folhas, em plantas de videira em casa de vegetação e em vinhedo orgânico. Determinou-se a atividade de superóxido dismutase (SOD) e peroxidase (POD) em folhas de videiras. EARU reduz em 58\% a germinação de P. viticola, 99,3\% e 50\% a AACPD do míldio em discos de folhas e em plantas em casa de vegetação, respectivamente. Porém em campo o EARU não apresentou diferença estatística com a testemunha. Em plantas em casa de vegetação a SOD foi semelhante para testemunha e EARU. Já em campo essa enzima não apresentou atividade. A POD apresentou aumento, nas plantas tratadas com EARU, de 60,34\% nas plantas em casa de vegetação e redução de $45 \%$ nas em campo. Conclui-se que o EABU apresenta potencial para o controle do míldio e ativação de enzimas de defesa de videiras cv. Margot, porém é necessária a otimização desses efeitos em plantas a campo.

Palavras-chave: Vitis vinifera; Manejo de doenças; Míldio; Superóxido dismutase; Peroxidase.

\begin{abstract}
The preparation of the wines was obtained with a large amount of residues that can be composted with antimicrobial and inductive action. In this sense, the objective of this study was to verify the action of aqueous extract of grape residue (AEGR) on the control of downy mildew and the activation of defense enzymes in cv. Margot. The treatments used were: 12\% AEGR, Saccharomyces cerevisae (Agro-Mos®), Bordeaux mixture (BM) and water (control). A germination test of Plasmopara viticola, area under the disease progression curve (UDPC) of downy mildew in leaf discs, grapevine plants under greenhouse conditions and organic vineyard were performed. The activity of the enzymes superoxide dismutase (SOD) and peroxidase (POD) on leaves of grapevines was determined. AEGR reduces
\end{abstract}


the germination of $P$. viticola by $58 \%, 99.3 \%$ and $50 \%$ the UDPC of the downy mildew in leaf discs and in greenhouse plants, respectively. However, in the field the AEGR did not present statistical difference with the control. It was observed that in greenhouse plants SOD was similar for control and AEGR and in the field this enzyme showed no activity. POD showed an increase of $60.34 \%$ in the plants treated with AEGR in the greenhouse and $45 \%$ in the field. The AEGR presents potential for the control of downy mildew and activation of cv. Margot, but it is necessary to optimize these effects in plants under field conditions.

Keywords: Vitis vinifera; Disease management; Downy mildew; Superoxide dismutase; Peroxidase.

\section{Resumen}

En la elaboración del vino se obtiene una gran cantidad de residuos que pueden contener compuestos con acción antimicrobiana e inductora. En este sentido, el objetivo de este trabajo fue verificar la acción del extracto acuoso de residuo de uva (EARU) en el control del mildiú velloso y activación de enzimas de defensa en vides cv. Margot. Los tratamientos utilizados fueron: EARU al 12\%, Saccharomyces cerevisae (Agro-Mos®), mezcla de Burdeos (CB) y agua (testigo). Se realizó prueba de germinación de Plasmopara viticola, área bajo la curva de progresión de la enfermedad (ABCPE) de mildiú velloso en discos foliares, en plantas de vid en invernadero y en viñedo orgánico. Se determinó la actividad de superóxido dismutasa (SOD) y peroxidasa (POD) en hojas de vid. EARU reduce la germinación de $P$. viticola en un 58\%, el mildiú velloso ABCPE en un 99,3\% y un 50\% en discos foliares y en plantas de invernadero, respectivamente. Sin embargo, en el terreno, la EARU no mostró ninguna diferencia estadística con el testigo. En plantas de invernadero, la SOD fue similar para el control y EARU. En el campo, esta enzima no mostró actividad. El POD mostró un incremento, en plantas tratadas con EARU, del 60,34\% en plantas en invernadero y una reducción del $45 \%$ en campo. Se concluye que EABU tiene potencial para controlar el mildiú velloso y activar las enzimas de defensa en la vid cv. Margot, sin embargo, es necesario optimizar estos efectos en las plantas de campo.

Palabras clave: Vitis vinifera; Manejo de enfermedad; Moho; Superóxido dismutasa; Peroxidasa.

\section{Introdução}

A produção de uvas no Brasil apresenta destaque nos estados de Rio Grande do Sul, Pernambuco, São Paulo, Santa Catarina e Paraná, que respondem a 94,5 \% da produção nacional. O estado gaúcho é o maior produtor de vinho com volume de 417,75 milhões de litros, no ano de 2018 (Mapa, 2018).

Um dos maiores problemas na viticultura são as doenças causadas por agentes patogênicos que podem reduzir drasticamente a qualidade e a quantidade de produção, dentre os quais encontra-se Plamopara viticola, agente causal do míldio, doença sérias em anos com elevada precipitação, alta umidade relativa e longos períodos de umidade sobre folhas e frutos e, em alguns anos são tão severas a ponto de comprometer não só a produção do ano como também produções futuras.

O controle mais eficaz é o químico, no entanto, como a vitivinicultura gera grande quantidade de resíduo de uva, resultante do processo de fermentação que contem, principalmente, casca e semente de uvas (Pereira et al., 2019), podendo, este subproduto ser uma opção na aplicação em plantas para o controle de doenças, pois em sua composição estão compostos fenólicos que podem apresentar efeito tóxico direto sobre microrganimos (Andreasson et al., 2017). A aplicação desse resíduo em tabaco levou à ativação de mecanismos de defesa dessas plantas, devido à sua ação elicitora (Benouaret et al., 2014).

Este subproduto da vitivinicultura corresponde a $50 \%$ da massa total da uva e trata-se de uma mistura complexa de compostos biotivos, como ligninas, estilbenos, ácidos fenólicos e favonóides, porém, apesar de todos esses compostos, esse subproduto é direcionado para compostagem ou descartado em áreas abertas, que podem ocasionar problemas ambientais. Assim é necessário a valorização da composição desse subproduto de forma que se possa ter um destino para o seu uso (Teixeira et al.,2014).

Dessa forma, o objetivo do trabalho foi verificar o efeito do extrato aquoso obtido do resíduo de uva no controle Plasmopara viticola e na ativação de enzimas de defesa em videiras cv. Margot.

\section{Metodologia}

\section{Obtenção do bagaço de uva e produtos utilizados}

O lote de resíduo de uva cv. Tannat foi obtido de uma vinícola do município de Bituruna-PR. Este material foi seco a 
$\pm 40^{\circ} \mathrm{C}$, em estufa com ar circulante, triturado em moinho e armazenado em sacos plásticos em câmara fria. A concentração utilizada nos experimentos foi $12 \%$ do extrato aquoso de resíduo de uva (EARU), obtido a partir da adição de água destilada a $70^{\circ} \mathrm{C}$ (infusão), e a proporção do resíduo moído (p:v). Esta dose baseou-se em testes preliminares in vitro.

Os tratamentos positivos foram Saccharomyces cerevisae, cepa 1026 (Agro-Mos®), na dose de $1 \mathrm{~L} \mathrm{ha}^{-1}$ e calda bordalesa $1 \%(\mathrm{~m} / \mathrm{v})(\mathrm{CB})$, além do tratamento testemunha (somente água e inoculada). A aplicação de produtos químicos não é autorizada em vinhedo orgânico, por isso foi utilizado S. cerevisae, pois segundo Zanardo et al. (2010) essa levedura apresenta a capacidade de atuar como elicitora para ativar mecanismos de defesa em plantas. Com esses tratamentos foram realizadas em pesquisas com bases em metodologias científicas (Pereira et al., 2018).

\section{Efeito do extrato aquoso de bagaço de uva na germinação de $P$. viticola}

A partir da ocorrência natural do míldio ( $P$. viticola) no campo, coletou-se folhas com sintomas da doença de plantas não tratadas. Para obter os esporângios de $P$. viticola, raspou-se a face abaxial das folhas com alça de Drigalski, posteriormente enxaguadas com água estéril.

Adicionou-se $40 \mu \mathrm{L}$ da suspensão de patógeno, calibrada em 104 esporângios $\mathrm{mL}^{-1}$ e $40 \mu \mathrm{L}$ de cada tratamento, individualmente, em cinco orifícios ("pocinhos") de uma placa utilizada em teste de ELISA. Em seguida essa placa foi armazenada em câmara climatizada (BOD) por 24 horas a $25^{\circ} \mathrm{C}$. Após esse período, adicionou-se $20 \mu \mathrm{L}$ de azul de lactofenol em cada "pocinho", para ocorrer a paralização da germinação dos esporângios de $P$. viticola. Foram considerados germinados os esporângios que apresentavam liberação dos zoósporos. Essa avaliação foi realizada em 100 esporângios por repetição.

O delineamento foi inteiramente casualizado com cinco repetições e quatro tratamentos. Os dados foram submetidos à análise da variância e posteriormente ao teste de Tukey $5 \%$ de probabilidade de erro, no programa estatístico Sisvar (Ferreira, 2011).

Efeito do extrato aquoso de bagaço de uva no controle do míldio em discos de folhas, em plantas de videira cv. Margot em casa de vegetação e em campo

Para o experimento em disco de folhas, foram coletadas folhas novas e sadias de plantas de videira cv. Margot, que em seguida foram desinfestadas em hipoclorito de sódio $0,1 \%$, durante 60 segundos, em álcool 70\%, durante 30 segundos, finalizando em água destilada para enxágue triplo. Após secagem das folhas em temperatura ambiente, foram cortadas em discos com $18 \mathrm{~mm}$ de diâmetro, com auxílio de perfurador manual. Os discos foram acondicionados sobre espumas úmidas em água destilada, contidas em bandejas plásticas individuais. Os tratamentos foram pulverizados sobre os discos de folhas e, após 24 horas, foi inoculado com suspensão de esporângios ( $1 \times 10^{4}$ esporângios $\left.\mathrm{mL}^{-1}\right)$ preparada conforme descrito em experimento anterior.

Os discos foliares foram inoculados via pulverização da suspensão de esporângios. Na sequência, as bandejas foram mantidas em câmara úmida a $25^{\circ} \mathrm{C}$ e fotoperíodo de 12 horas. A partir dos primeiros sintomas, seis dias após inoculação, foi avaliada a severidade do míldio utilizando a escala diagramática de Azevedo (1997). A avaliação da severidade foi executada diariamente em microscópio estereoscópico.

Para o experimento conduzido em casa de vegetação, foram plantadas mudas de videira cv. Margot em setembro de 2015, em vasos com capacidade de 3 L, contendo substrato comercial (Plantmax ${ }^{\circledR}$, composto por casa de árvores) e com irrigação por aspersão. As pulverizações dos tratamentos foram semanais, sempre nas horas mais frescas do dia e se deu início a partir da completa brotação das gemas, sendo no período de 10/02/2015 a 13/03/2015.

Na completa brotação das gemas, em 12/02/2015 realizou-se a inoculação de $5 \times 10^{4}$ esporângios $\mathrm{mL}^{-1}$ de $P$. viticola e manteve-se as plantas em câmara úmida por 24 horas para favorecer a germinação do patógeno. Após quatro dias da 
inoculação (16/02/2015), observaram-se os primeiros sintomas do míldio. As avaliações da doença foram realizadas semanalmente em três folhas previamente identificadas, do ápice de três ramos por planta, totalizando cinco. Para a determinação da severidade do míldio utilizou-se a escala diagramática de Azevedo (1997) e em seguida realizou-se a transformação desses dados, segundo Shaner e Funney (1977), em área abaixo da curva do progresso da doença (AACPD).

Após 24 horas de inoculação do patógeno (13/02/2015), realizou-se, nessas plantas, a coleta de discos de folhas para determinação da atividade das enzimas superóxido dismutase (SOD) e peroxidase (POD).

O experimento realizado em campo foi conduzido em vinhedo orgânico, cv. Margot em porta enxerto 'Paulsen 1103' com dois anos de idade, durante o ciclo de 2014/2015, em sistema espadeira, com espaçamento 3,0 X 2,0 m, irrigação por gotejamento, localizado no município de Guarapuava-PR, com latitude de $25^{\circ} 23^{\prime} 36^{\prime}$ 'S, longitude de $51^{\circ} 27^{\prime} 19^{\prime}$ 'O e altitude de $1.120 \mathrm{~m}$. A classificação do solo é latossolo bruno distroférrico de textura argilosa. O clima é definido como Cbf subtropical mesotérmico úmido, conforme classificação de Köppen (Ayoade, 1998). Durante o experimento a média da temperatura e umidade foram de $26,6{ }^{\circ} \mathrm{C}$ e $95 \%$, respectivamente.

As aplicações dos tratamentos foram realizadas semanalmente no período de 10/11/2014 a 02/03/2015 sempre nas horas mais frescas do dia, a partir do inicio da completa brotação das gemas.

A partir dos primeiros sintomas, ocorrido naturalmente, em 23/02/2015, iniciou-se a avaliação da severidade do míldio em três folhas do ápice de três ramos por planta, previamente identificadas, utilizando-se uma escala diagramática de Azevedo (1997). Com os dados da severidade foi determinada a área abaixo da curva de progresso da doença (AACPD), proposta por Shaner e Funney (1977).

Também nessas plantas foi realizada coleta de discos de folhas para determinar a atividade das enzimas SOD e POD. Esse procedimento foi realizado em 03/03/2015, 24 horas após a aplicação dos tratamentos.

O delineamento dos experimentos com discos de folhas e em plantas em casa de vegetação foi inteiramente casualizado e o a campo em blocos ao acaso. O ensaio com disco de folha apresentou cinco repetições compostas com oito discos de folhas e seis tratamentos, os da casa de vegetação e em campo, foram cinco tratamentos e quatro repetições. Os resultados foram submetidos à análise de variância e posteriormente ao teste de Tukey $5 \%$ de probabilidade de erro, no programa Sisvar (Ferreira, 2011).

\section{Coleta e armazenamento das amostras de videiras cv. Margot, cultivadas em casa de vegetação e em campo, para análise de enzimas}

Para avaliar a ação de enzimas oxidativas na defesa da videira contra o agente causal do míldio, 24 horas após a inoculação do patógeno, realizou-se coleta de folhas de videira.

As folhas foram armazenadas em papel alumínio, refrigerados em nitrogênio e, em seguida, acondicionadas em freezer a $-20^{\circ} \mathrm{C}$ até o preparo de extratos utilizados nas análises.

Em seguida foram pesados, macerados em almofariz com nitrogênio líquido e homogeneizados mecanicamente em 4 $\mathrm{mL}$ de tampão fosfato de potássio $50 \mathrm{mM}(\mathrm{pH}$ 7) contendo $0,1 \mathrm{mM}$ de EDTA. Essa solução foi transferida para tubo tipo eppendorf contendo $0,0003 \mathrm{~g}$ de polivinilpirrolidona (PVP) e centrifugado a $15000 \mathrm{~g}$ durante 40 minutos a $4^{\circ} \mathrm{C}$.

O extrato enzimático foi obtido do sobrenadante dessa centrifugação, que em seguida, foi armazenado em freezer $20^{\circ} \mathrm{C}$, até a realização das análises do conteúdo protéico, atividade das enzimas superóxido dismutase (SOD) e peroxidase (POD).

\section{Determinação do conteúdo protéico total}

Para a determinação do conteúdo protéico total foi utilizado $100 \mu \mathrm{L}$ do extrato enzimático adicionado sob agitação em 
2,5 mL do reagente Bradford. Passados 5 minutos foi efetuada a leitura em espectrofotômetro com comprimento de onda de $595 \mathrm{~nm}$. A concentração de proteínas, expressa $\mathrm{em} \mathrm{mg}$ por $\mathrm{mL}$ de amostra $\left(\mathrm{mg}\right.$ proteína $\left.\mathrm{mL}^{-1}\right)$, foi determinada utilizando-se curva-padrão de concentrações de albumina de soro bovino (ASB) de 0 a $0,5 \mathrm{mg} \mathrm{mL}^{-1}$, obtida pelo método de Bradford (Bradford, 1976).

\section{Determinação da atividade de superóxido dismutase (SOD E.C. 1.15.1.1) e peroxidases (POD E.C. 1.11.1.7)}

Para a determinação da atividade específica da enzima superóxido dismutase (SOD) (E.C. 1.15.1.1) preparou-se solução contendo $125 \mathrm{~mL}$ de tampão fosfato de potássio à $0,105 \mathrm{M}$ e pH7,8; $250 \mu \mathrm{L}$ de EDTA à $0,1 \mathrm{mM} ; 15 \mathrm{mg}$ de

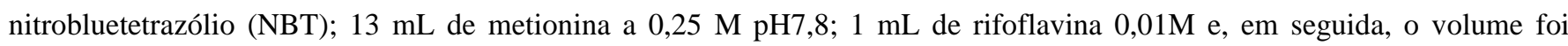
completado para $250 \mathrm{~mL}$ com água destilada (Giannopolitis \& Reis, 1977).

Em placas de cultivo de células contendo 24 poços e com fundo chato e capacidade máxima para $3,5 \mathrm{~mL}$ foram adicionadas $25 \mu \mathrm{L}$ do extrato enzimático e $3 \mathrm{~mL}$ dessa solução. Esse procedimento foi realizado em duas placas, porém uma ficou exposta à luz por 10 minutos e a outra no escuro, como controle. Posteriormente, ambas, foram lidas em espectrofotômetro (modelo UV-1800, Shimadzu Corporation, Kyoto, Japão) a $560 \mathrm{~nm}$.

Para a quantificação da atividade específica de SOD, expressa em U $\mu \mathrm{g}$ proteína ${ }^{-1}$, multiplicou-se a porcentagem de inibição pelo volume da amostra e, em seguida, dividiu-se pela multiplicação de $50 \%$ pela concentração de proteína total da amostra $\left(\mu \mathrm{g} \mu \mathrm{L}^{-1}\right)$. Com isso verificou-se a formação de formazona proveniente da redução do NBT na presença de luz.

Dessa forma, 1 unidade de SOD representa 50\% de inibição da fotoredução do NBT (Giannopolitis \& Reis, 1977).

A atividade da peroxidase de guaiacol (POD) (EC 1.11.1.7) foi determinada pelo método espectrofotométrico direto, medida da conversão do guaiacol em tetraguaiacol em $470 \mathrm{~nm}$, à $30{ }^{\circ} \mathrm{C}$ (Lusso \& Pascholati, 1999). A mistura da reação continha $0,1 \mathrm{~mL}$ do extrato enzimático e $2,0 \mathrm{~mL}$ de solução com $250 \mu \mathrm{L}$ de guaiacol e $306 \mu \mathrm{L}$ de peróxido de hidrogênio em $100 \mathrm{~mL}$ de tampão fosfato $0,01 \mathrm{M}$ (pH 6,0). A cubeta de referência continha $3 \mathrm{~mL}$ da solução de guaiacol e peróxido de hidrogênio em tampão fosfato. A atividade da peroxidase foi determinada por um período de 2 minutos, e utilizou-se a média dos valores da leitura que apresentaram no mínimo três pontos crescentes, obtendo assim uma reta. Os resultados foram expressos em absorbância $\min ^{-1} \mathrm{mg}^{-1}$ de proteína.

O delineamento experimental foi inteiramente casualizado com quatro tratamentos e quatro repetições. Os resultados foram submetidos a análise de variância e quanto significativo ao teste de Tukey (5\%) no programa estatístico Sisvar (Ferreira, 2011).

\section{Resultados e Discussão}

\section{Efeito do extrato aquoso de bagaço de uva na germinação de Plasmopara viticola}

O EARU reduziu em aproximadamente $58 \%$ a germinação de $P$. viticola, e não apresentou diferença estatística em relação aos tratamentos positivos (Figura 1). Esse percentual de redução da germinação interfere de forma positiva com o controle do patógeno P. viticola que colabora com a redução da AACPD do míldio (Garcia et al., 2021). 
Figura 1. Germinação de esporângios de Plasmopara viticola após 24 horas a $25^{\circ} \mathrm{C}$ imersos nos tratamentos com extrato aquoso de resíduo de uva (EARU), Saccharomyces cerevisae, calda bordalesa (CB) e testemunha. *Médias seguidas de mesma letra não diferem entre si pelo teste de Tukey a 5\% de probabilidade.

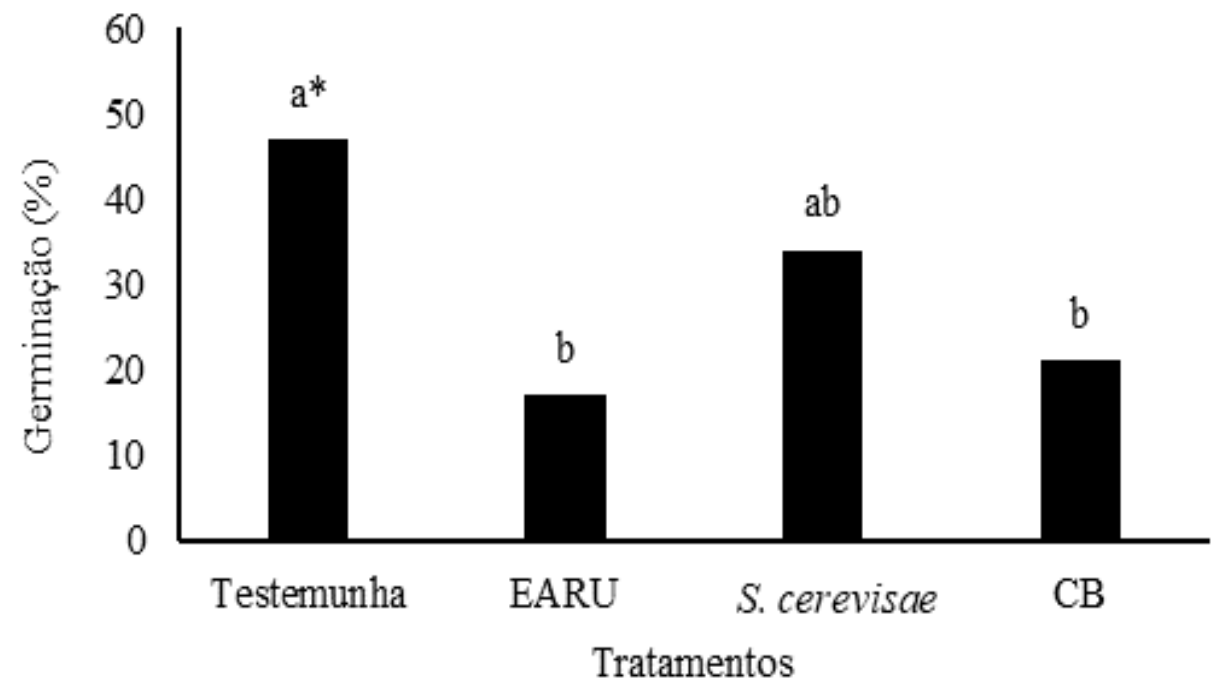

Fonte: Autores.

A composição fenólica do subproduto da indústria de uva, possivelmente, está relacionada com a redução da germinação do patógeno (Andreasson et al., 2017). Esses compostos atuam diretamente sobre os microrganismos aumentando a permeabilidade da membrana plasmática das células, ocasionando a lise celular e, consequentemente, a perda do conteúdo da célula. Com isso tem-se a redução da germinação do patógeno e perda da sua viabilidade (Martínez et al., 2017).

Esses efeitos dos compostos fenólicos também são evidenciados com a completa inibição da germinação de zoósporos de $P$. viticola em contato com a dose de $100 \mathrm{mg} \mathrm{L}^{-1}$ e a liberação dessas estruturas $100 \%$ inibida com $330 \mathrm{mg} \mathrm{L}^{-1}$ de extrato de estilbenoide, dito Veneatrol obtido de Vitis vinifera (Richard et al., 2016).

Efeito do extrato aquoso de bagaço de uva no controle do míldio em discos de folhas, em plantas de videira cv. Margot em casa de vegetação e em campo

Com relação à AACPD do míldio ( $P$. viticola) nos discos de folhas, observou-se que o EARU reduziu em 99,3\%, em relação à testemunha, não apresentando diferença estatística com os tratamentos com S. cerevisae e CB (Figura 2). 
Figura 2. Área abaixo da curva do progresso de doença (AACPD) da severidade do míldio (Plasmopara viticola) em discos de folha de videira cv. Margot tratados com extrato aquoso de resíduo de uva (EARU), Saccharomyces cerevisae, calda bordalesa (CB) e testemunha. *Médias seguidas de mesma letra não diferem entre si pelo teste de Tukey a 5\% de probabilidade de erro.

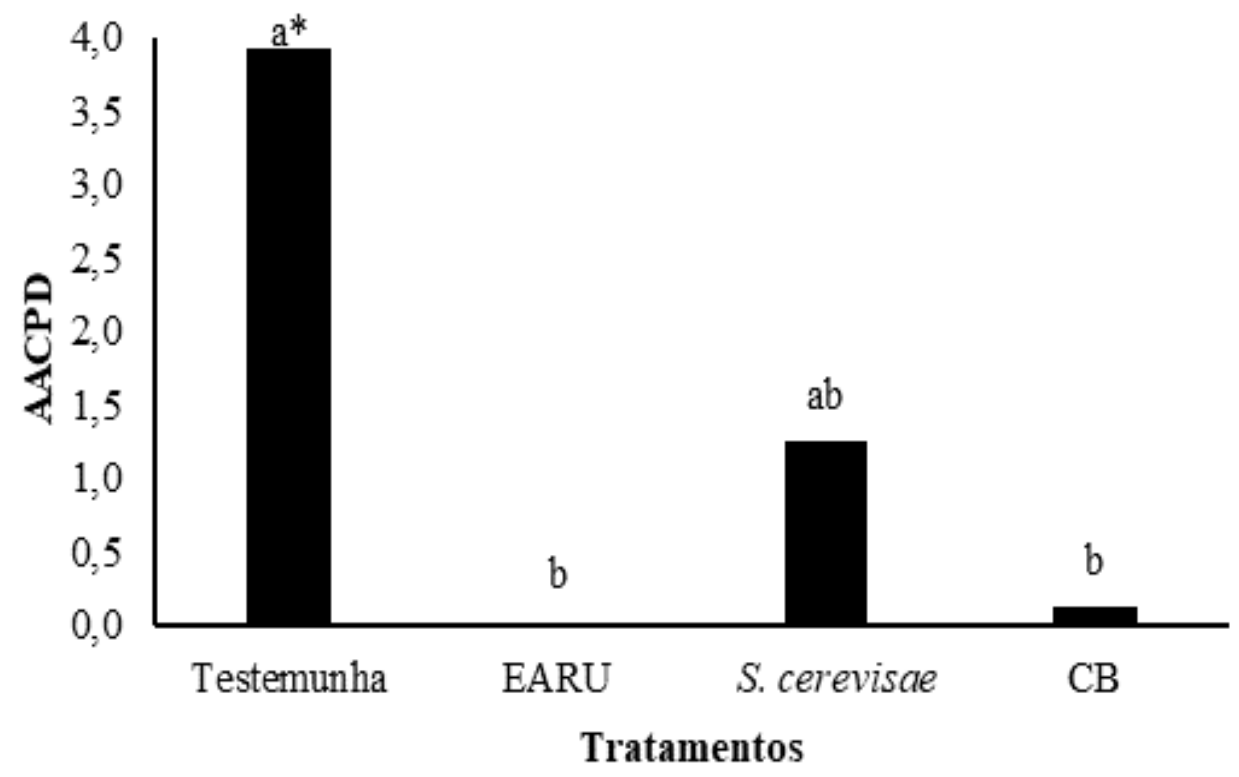

Fonte: Autores.

Nas plantas mantidas em casa de vegetação, o EARU reduziu em cerca de 50\% a AACPD do míldio em videiras cv. Margot em relação à testemunha, não apresentado diferenças estatísticas com S. cerevisae e CB (Figura 3).

Figura 3. Área abaixo da curva do progresso de doença (AACPD) de míldio (Plasmopara viticola) em videira cv. Margot, em casa de vegetação tratadas com com extrato aquoso de resíduo de uva (EARU), Saccharomyces cerevisae, calda bordalesa (CB) e testemunha. *Médias seguidas de mesma letra não diferem entre si pelo teste de Tukey a 5\% de probabilidade.

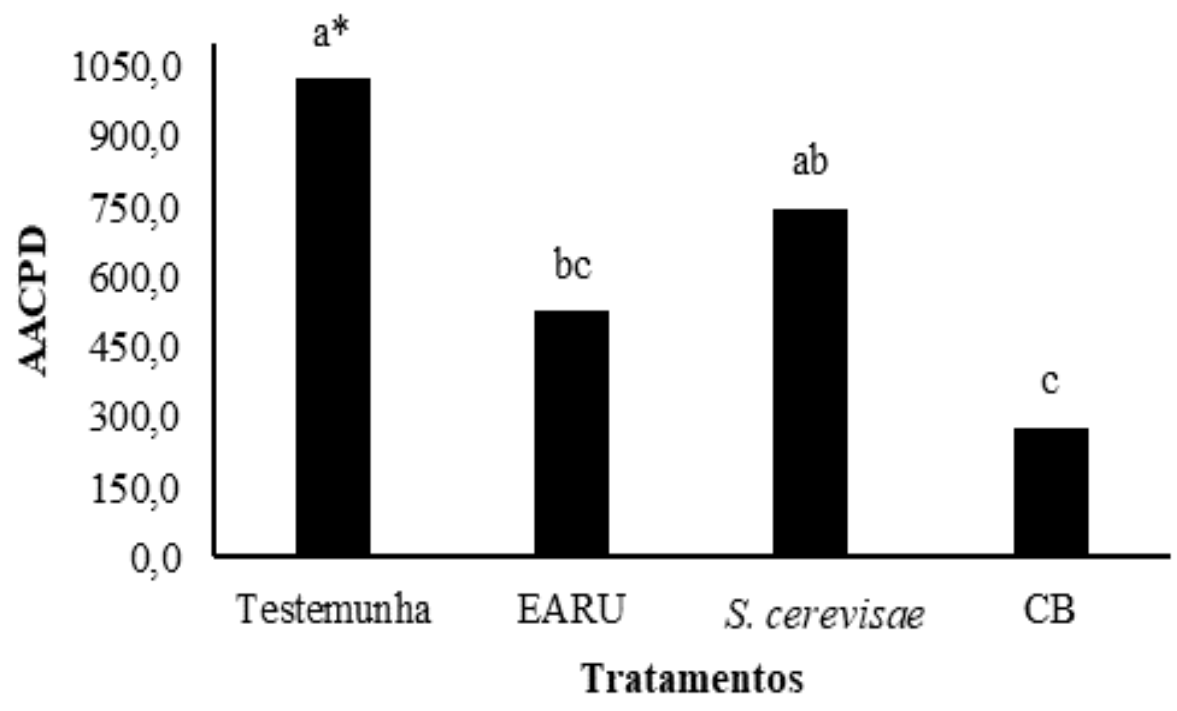

Fonte: Autores. 
No campo, o EARU não apresentou diferença estatística em relação aos tratamentos testemunha e com S. cerevisae (Figura 4).

Figura 4. Área abaixo da curva do progresso de doença (AACPD) de míldio (Plasmopara viticola) em videira cv. Margot, em campo, tratadas com extrato aquoso de resíduo de uva (EARU), Saccharomyces cerevisae, calda bordalesa (CB) e testemunha. *Médias seguidas de mesma letra não diferem entre si pelo teste de Tukey a 5\% de probabilidade.

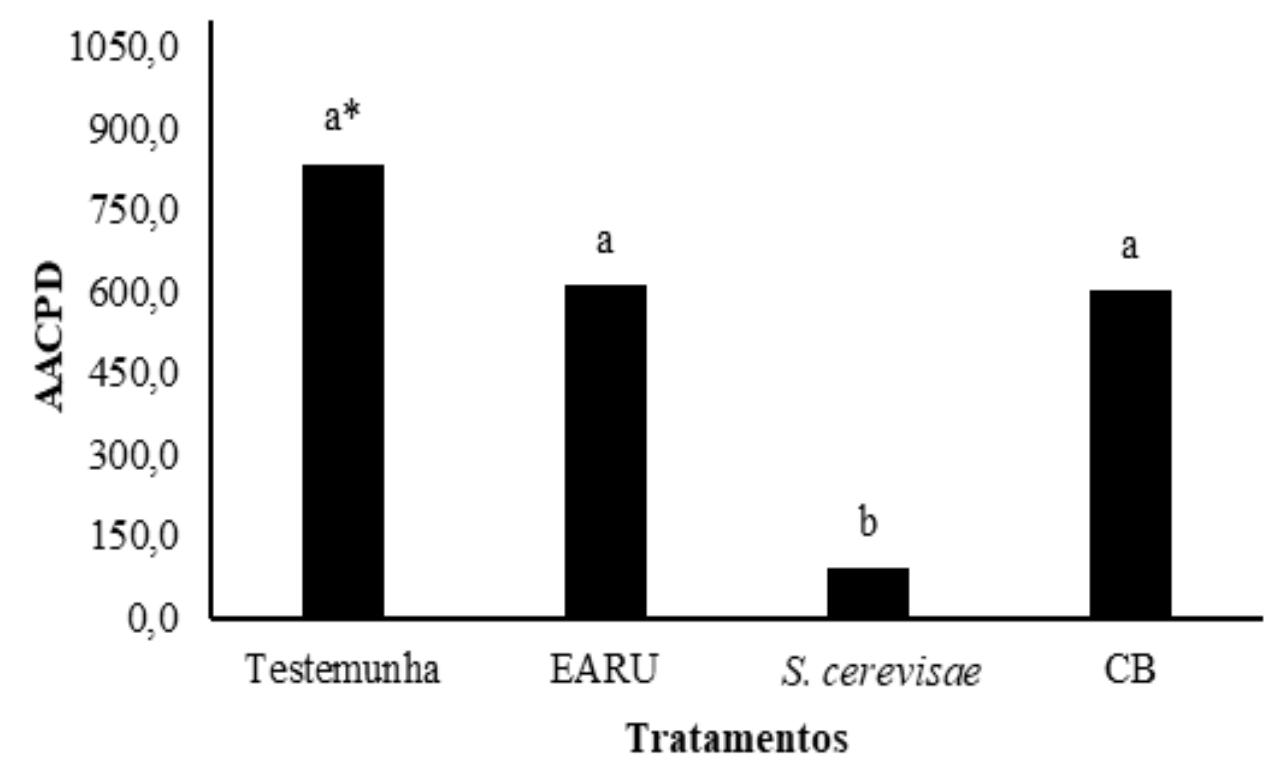

Fonte: Autores.

Os estilbenos são compostos fenólicos presentes no EARU e podem bloquear a infecção do $P$. viticola pelo impedimento da entrada dos zoósporos nas folhas de videira por inibir seus movimentos (Gabaston et al., 2017). Adicionalmente, esses compostos apresentam toxicidade sobre os microrganismos causando alterações nas membranas celulares. Assim, podem danificar as membranas celular microbiana, induzir a condensação do nucleóide, formação de vesículas citoplasmáticas, inibir parcialmente a síntese de DNA e de proteínas, que refletem na redução do crescimento celular (Kim et al., 2013). Além disso, pode ocorrer a geração de espécies reativas ao oxigênio (EROs) que também danificam as membranas plasmáticas dos patógenos acarretando na apoptose celular devido ao vazamento do conteúdo das células ( Koh et al., 2016).

Nos entanto, em condições de campo, estes efeitos não foram verificados como nos experimentos em discos de folha e em casa de vegetação. No presente estudo tivemos altas temperaturas, chegando a $31^{\circ} \mathrm{C}$ e uma soma de pluviosidade de 1026 $\mathrm{mm}$. Assim, estas diferenças de resposta podem estar relacionadas com a volatilização, degradação e lavagem dos compostos presentes no EARU. Isto pode acontecer uma vez que os compostos fenólicos, como os estilbenos, principalmente o resveratrol, possuem sensibilidade à intensidade luminosa e à temperatura elevada (Madureira et al., 2018).

Dessa forma sugere-se utilizar adjuvantes junto ao EABU para que se possa otimizar seus efeitos de controle do míldio em videiras, reduzindo assim a volatilização, degradação e/ou lavagem de seus compostos bioativos.

Apesar da CB apresentar resultados satisfatórios para o controle do míldio, sua aplicação pode ser restringida futuramente, pois proporciona contaminações de cobre no solo e na água subterrânea ocasionando desiquilíbrios de nutrientes e elevação dos teores de elementos tóxicos (Tröster et al., 2017). Esse mesmo problema se remete ao tratamento com $S$. cerevisae, pois seu efeito antimicrobiano, também, está relacionado, principalmente, a presença de cobre na formulação do produto comercializado (Costa et al., 2007). 


\section{Determinação da atividade de superóxido dismutase (SOD E.C. 1.15.1.1) e peroxidases (POD E.C. 1.11.1.7)}

A atividade da enzima superóxido dismutase (SOD) nas plantas em casa de vegetação não apresentou diferenças estatísticas entre os tratamentos com EARU e testemunha. Porém os tratamentos com S. cerevisae e CB aumentaram a atividade da SOD em, aproximadamente 2 mil e 400 vezes, em relação a testemunha (Figura 5). Nas videiras cv. Margot em campo a SOD não apresentou atividade.

Figura 5. Atividade da enzima superóxido dismutase (SOD) em plantas de videira cv. Margot tratadas com ex trato aquoso de resíduo de uva (EARU), Saccharomyces cerevisae, calda bordalesa (CB) e testemunha em casa de vegetação. *Médias seguidas de mesma letra não diferem entre si pelo teste de Tukey a 5\% de probabilidade.

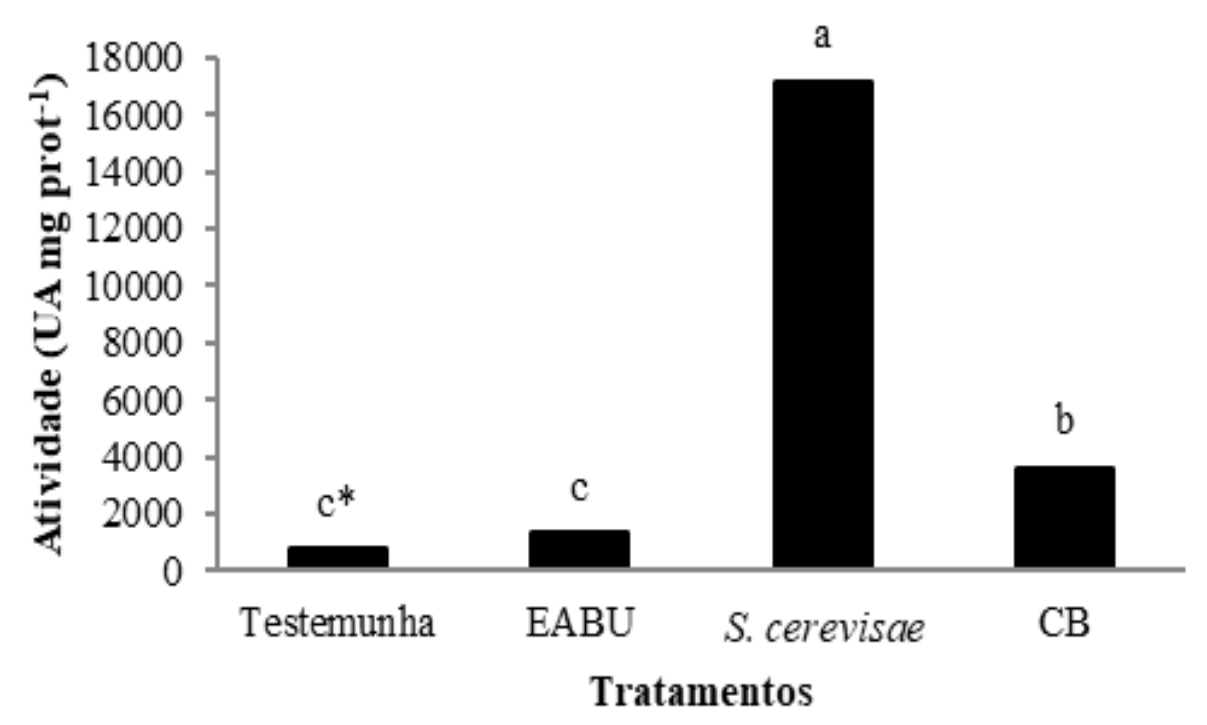

Fonte: Autores.

A semelhança de efeitos do EARU e a testemunha podem estar relacionada ao fato de que a parede celular do $P$. viticola ser composta, principalmente, por $\beta$-glucanas e os polímeros dessa estrutura podem apresentar atividade elicitora ativando, mesmo que em baixas atividades, mecanismos de defesa das plantas (Fesel \& Zuccaro, 2016).

Esse processo ocorre devido a alterações no potencial transmembranas, que leva a entrada de $\mathrm{H}^{+}$e $\mathrm{Ca}^{2+}$ e a saída de $\mathrm{K}^{+}$e $\mathrm{Cl}^{-}$, com isso tem-se a ativação das espécies reativas ao oxigênio (EROs). Dentre as EROs está o íon superóxido $\left(\mathrm{O}_{2}{ }^{-}\right)$ dismutado pela enzima superóxido dismutase (SOD) e o peróxido de hidrogênio $\left(\mathrm{H}_{2} \mathrm{O}_{2}\right)$ que pode servir como substrato para a enzima peroxidase (POD). Essas enzimas reduzem o efeito tóxico dessas moléculas nas células vegetais (Baxter et al., 2014).

A SOD é a primeira linha de defesa para a desintoxicação das EROs em que catalisa a reação em que o $\mathrm{O}_{2}{ }^{-}$é dismutado em $\mathrm{H}_{2} \mathrm{O}_{2}$ e $\mathrm{O}_{2}$. Com isso tem-se o inicio da ativação dos mecanismos de defesa ativados nas plantas (Yadav et al., 2019). Reação, que possivelmente, ocorreu nas plantas tratadas com S. cerevisae, porém, não se mostrou efetivo para o controle do míldio nessas plantas. Esse fato pode estar relacionado com a ausência de transdução de sinal proporcionada pelos íons de $\mathrm{Ca}^{2+}$ na membrana (Gauthier et al., 2014).

Quanto à atividade da POD nas videiras cv. Margot, em casa de vegetação, verificou-se aumento em sua atividade em 60,34\% nas plantas tratadas com EARU e 200\% nas com CB, em relação ao tratamento testemunha (Figura 7A).

Porém em condições de campo, o EARU reduziu em, aproximadamente, $45 \%$ a atividade de POD e a CB aumentou em $399 \%$, em relação à testemunha (Figura 7B). 
Figura 6. Atividade da enzima peroxidase (POD) em discos de folhas coletados de plantas cv. Margot tratadas com extrato aquoso de resíduo de uva (EARU), Saccharomyces cerevisae, calda bordalesa (CB) e testemunha, cultivadas em casa de vegetação (A) e em campo (B). *Médias seguidas de mesma letra não diferem entre si pelo teste de Tukey a 5\% de probabilidade.
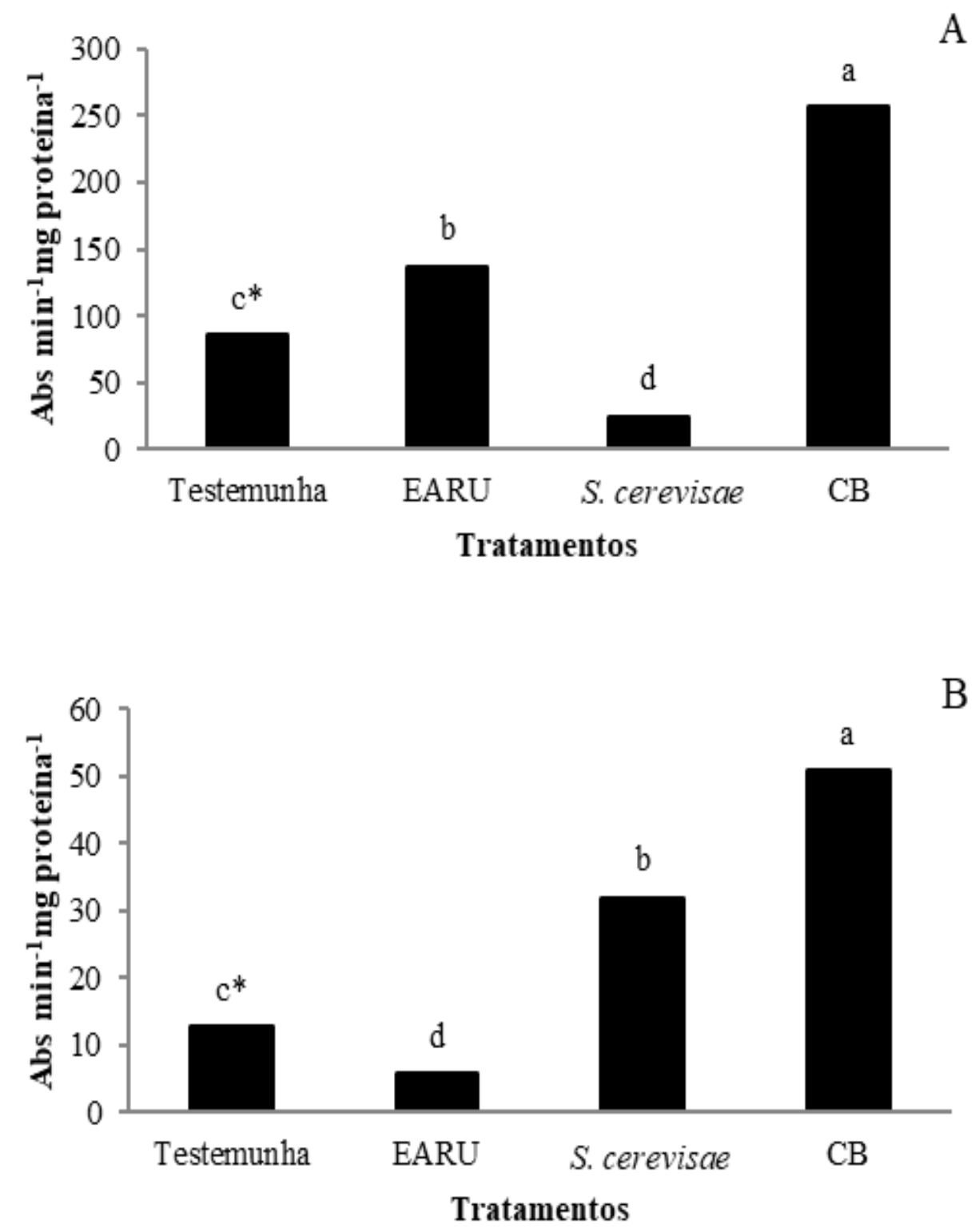

Fonte: Autores.

A elevada atividade de POD está relacionada ao aumento da deposição de lignina nas células dos vegetais. Esse processo ocorre devido à ação dessa enzima em realizar a oxidação de $\mathrm{H}_{2} \mathrm{O}_{2}$ em radicais de monolignol fenoxi que se pareiam espontaneamente formando polímeros de lignina depositados na parede celular. Com isso tem-se a lignificação da parede celular e o seu fortalecimento, formando uma barreira física efetiva de difícil degradação do patógeno e, portanto, pode-se resultar no impedimento no processo de infecção (Diniz et al., 2019).

Em plantas de tabaco também foi observado que o extrato de bagaço de uva apresenta efeito elicitor ativando enzimas de defesa e atuam de forma tóxica sobre o oomiceto Phytophthora parasitica (Benorearet et al., 2014). 
Baseado nos resultados verifica-se que o EARU apresenta resultados promissores para o controle do míldio em videiras cv. Margot e também como indutor de resistência nessas plantas. Porém, em condições de campo novas pesquisas devem ser realizadas, principalmente, em relação à associação desse extrato com adjuvantes para otimizar seus efeitos de controle e de indutor de resistência ao míldio.

\section{Conclusão}

O EARU reduz a germinação de $P$. viticola;

O EARU diminui a AACPD do míldio em discos de folhas e em plantas de videira cv. Margot, acondicionadas em casa de vegetação;

Esse extrato apresenta potencial para atuar como elicitor na ativação de mecanismos de defesa dessas plantas;

Sugere-se que novas pesquisas sejam realizadas em condições de campo com a associação de adjuvantes ao EARU.

\section{Referências}

Andreasson, E., Marit, L. \& Laith M. (2017). Plant extracts comprising at least a phenolic compound, for inducing the natural defense of a plant against a pathogen, such as Phytophthora infestans. United States Patent, 9, 669-681.

Ayoade, J. O. Introdução a climatologia para os trópicos (1998). trad. Maria Juraci Zani dos Santos. Bertrand Brasil, 350p.

Azevedo, L. A. S. (1997). Manual de quantificação de doenças de plantas. Novartis Biociências- Setor Agro, 114p.

Baxter, A., Mittler, R. \& Uzuki, N. (2014). ROS as key players in plant stress signalling. Journal Experimental Botany, 65(5), 1229-1240.

Benouaret, R., Goujon, E. \& Goupil, P. (2014). Grape marc extract causes early perception events, defence reactions and hypersensitive response in cultured tobacco cells. Plant Physiology and Biochemistry, 77, 84-89.

Bradford, M. M. (1976). A rapid and sensitive method for the quantitation of microgram quantities of protein utilizing the principle of protein-dye binding. Analytical Biochemistry, 72 (1-2), 248-254.

Costa, M. J., Zambolim, L. \& Rodrigues, F. A. (2007). Avaliação de produtos alternativos no controle da ferrugem do cafeeiro. Fitopatologia Brasileira, 32 (2), 150-155.

Diniz, I., Azinheira, H., Figueiredo, A., Gichuru, E., Oliveira, H., Guerra-Guimaraes, L. \& Silva, M. C. (2019). Fungal penetration associated with recognition, signaling and defence-related genes and peroxidase activity during the resistance response of coffee to Colletotrichum kahawae. Physiological and Molecular Plant Pathology, 105, 119-127.

Ferreira, D. F. (2011). Sisvar: a computer statistical analysis system. Ciência e Agrotecnologia, 35, 1039-1042.

Fesel, P.H. \& Zuccaro, A. (2016). B-glucan: Crucial component of the fungal cell wall and elusive MAMP in plants. Fungal Genetics and Biology, 90, 53-60.

Garcia, C., Fedrigo, K., Gabriel, A., Botelho, R. V., Rodrigues, J. D., \& Ono, E. O. (2021). Control of mildew in vines with cinnamon extract and catalase activity in organic production. Research, Society and Development, 10, 1-10.

Gabaston, J., Richard, T., Biais, B., Waffo-Teguo, P., Pedrot, E., Jourdes, M., \& Mérillon, J. M. (2017). Stilbenes from common spruce (Picea abies) bark as natural antifungal agent against downy mildew (Plasmopara viticola). Industrial Crops and Products, 103, $267-273$.

Gauthier, A., Trouvelot, S., Kelloniemi, J., Frettinger, P., Wendehenne, D., Daire, X., \& Poinssot, B. (2014). The sulfated laminarin triggers a stress transcriptome before priming the SA-and ROS-dependent defenses during grapevine's induced resistance against Plasmopara viticola. PLoS One, 9 , e88145.

Giannopolitis, C. N. \& Ries, S. K. (1977). Superoxide dismutases. I. Occurrence in higher plants. Plant Physiology, 59, 309-314.

Kim, N., Kim, J. K, Hwang, D, \& Lim, Y. H. (2013). The possible mechanism of rhapontigenin influencing antifungal activity on Candida albicans. Medical mycology, 51, 45-52.

Koh, J. C., Barbulescu, D. M., Salisbury, P. A., \& Slater, A. T. (2016). Pterostilbene is a potential candidate for control of blackleg in canola. PLoS One, 11, e0156186.

Lusso, M. F. G. \& Pascholati, S. F. (1999). Activity and isoenzymatic pattern of soluble peroxidases in maize tissues after mechanical injury or fungal inoculation. Summa Phytopathologica, 25, 244-249.

Madureira, J., Barros, L., Melo, R., Verde, S. C., Ferreira, I. C., \& Margaça, F. M. A. (2018). Degradation of phenolic acids by gamma radiation as model compounds of cork wastewaters. Chemical Engineering Journal, 341, 227-237.

Martínez, G., Regente, M., Jacobi, S., Del Rio, M., Pinedo, M., \& De La Canal, L. (2017). Chlorogenic acid is a fungicide active against phytopathogenic fungi. Pesticide Biochemistry and Physiology, 140, 30-35. 
Research, Society and Development, v. 10, n. 11, e453101119908, 2021

(CC BY 4.0) | ISSN 2525-3409 | DOI: http://dx.doi.org/10.33448/rsd-v10i11.19908

Ministério da agricultura, pecuária e abastecimento. MAPA-2018. Projeções do agronegócio, 2018. http://www.agricultura.gov.br/assuntos/politicaagricola/todas-publicacoes-de-politica-agricola/projecoes-doagronegocio/PROJECOES2018_FINALIZADA_web_050 92018.pdf?fbclid=I wAR1E_suqSIA OOAtv1bGME1J4Bab5uNbnz612uwBoaBZIpZWHA2kKyBYQotA

Pereira, A. S., Shitsuka, D. M., Parreira, F. J., \& Shitsuka, R. (2018). Metodologia da pesquisa científica. UFSM. 5.3.

Pereira, D. T. V., Tarone, A. G., Cazarin, C. B. B., Barbero, G. F. \& Martínez, J. (2019). Pressurized liquid extraction of bioactive compounds from grape marc. Journal of Food Engineering, 240, 105-113.

Richard, T., Abdelli-Belhad, A., Vitrac, X., Waffo-Téguo, P., \& Mérillon, J. M. (2016). Vitis vinifera canes, a source of stilbenoids against downy mildew. Oeno One, 50, 137-143.

Shaner, G. \& Finney, R. (1977). The effect of nitrogen fertilization on the expression of slow mildewing resistance in Knox Wheat. Journal of Phytopathology, 67, 1051-1056.

Teixeira, A., Baenas, N., Dominguez-Perles, R., Barros, A., Rosa, E., Moreno, D. A., \& Garcia-Viguera, C. (2014). Natural bioactive compounds from winery by-products as health promoters: A review. International Journal of Molecular Sciences, 15, 15638-15678.

Tröster, V., Setzer, T., Hirth, T., Pecina, A., Kortekamp, A. \& Nick, P. (2017). Probing the contractile vacuole as Achilles' heel of the biotrophic grapevine pathogen Plasmopara viticola. Protoplasma, 254, 1887-1901.

Yadav, S., Gill, S. S, Passricha, N., Gill, R., Badhwar, P., Anjum, N. A., \& Tuteja, N. (2019). Genome-wide analysis and transcriptional expression patternassessment of superoxide dismutase (SOD) in rice and Arabidopsis under abiotic stresses. Plant Gene, 17, 1-9.

Zanardo, N. M. T, Pascholati, S. F, \& Fialho, M. B. (2010). Resistência de plântulas de pepineiro a Colletotrichum lagenarium induzida por frações de extrato de Saccharomyces cerevisiae. Pesquisa Agropecuária Brasileira, 44, 1499-1503. 